\title{
Exploring the meanings of male partner involvement in the prevention of MTCT of HIV in Zimbabwe
}

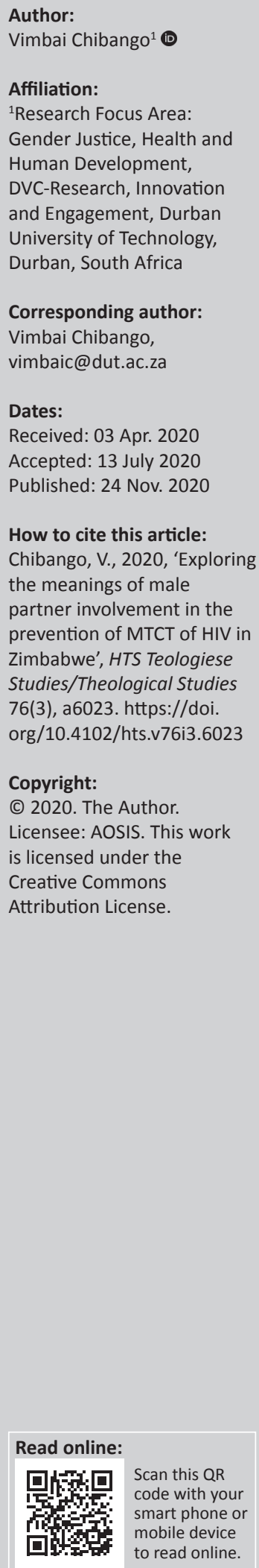

Male partner involvement (MPI) in the prevention of mother-to-child transmission (PMTCT) of human immunodeficiency virus (HIV) is considered as one of the priority interventions in reducing paediatric HIV. However, there is neither a standard definition nor measurement for MPI in PMTCT. The study explored meanings of MPI in PMTCT programmes in Zimbabwe. Eight focus group discussions (FGDs) were conducted with men and women aged 18 years and above. Seven key informants (KII) from health institutions and organisations providing PMTCT services were interviewed. Eight in-depth interviews (IDIs) were conducted with pregnant women at two public health facilities. Thematic analysis was used for data analysis. Five major themes were identified which facilitated our understanding of MPI. Male partner involvement was referred to as participation of male partners in HIV couple counselling and testing. Acceptance of condom use during pregnancy and breastfeeding was deemed vital as this prevents HIV transmission. Male partners were expected to have knowledge of administering antiretroviral drugs to an HIV-exposed child. Provision of financial support was another form of male involvement commonly expected during antenatal and postnatal periods. Faithfulness in marriage was a major theme that was highlighted, especially by respondents in marital relationships. Male partner presence in PMTCT community educational sessions was also considered. However, the provision of male-oriented educational programmes was identified as poor. The study suggested a definition for MPI in PMTCT in Zimbabwe. The merit of this definition was that it took a holistic approach to include activities beyond antenatal activities and HIV testing. Future research should explore how public health institutions could create male-oriented health services within PMTCT programmes, as this has the potential of increasing men's involvement in PMTCT of HIV.

Contribution: This article contributed to the knowledge on how world views, which is shaped by culture and religion, influenced the formation of meanings on MPI PMTCT programmes.

Keywords: Male partner involvement; PMTCT; HIV; Definition; HIV prevention; Zimbabwe.

\section{Introduction}

Male partner involvement (MPI) in the prevention of mother-to-child transmission (PMTCT) of human immunodeficiency virus (HIV) is considered as one of the priority interventions in reducing paediatric HIV. However, a number of studies in the global south show that progress in the efforts to eliminate mother-to-child transmission of HIV has been hampered by no or low male partner support (Bwambale et al. 2008; OPHID 2015; Orne-Gliemann et al. 2010; Påfs et al. 2015; Theuring et al. 2009; Tshibumbu 2006), yet they play a significant role in decision-making processes that can affect women's utilisation of healthcare services. The level of male partner support, however, is influenced by an understanding of what MPI refers to in any given culture. Male partner involvement in PMTCT is a concept that has no universal or standard definition (Aluisio et al. 2011; Ditekemana et al. 2012; Montgomery, Van der Straten \& Torjesen 2011), and thus, different studies have attempted to formulate meanings that suit their specific contexts. The lack of a standard definition of MPI is the motivation for this article, to explore how this concept is understood in a rural district of Zimbabwe.

Low levels of male involvement in PMTCTC programmes, amongst other factors, resulted from the historic institutionalisation of reproductive health, especially maternal and child health as a domain

Note: Special Collection entitled Gender Justice, Health and Human Development, sub-edited by Cheryl Potgieter (DUT). 
for women only. This led men to perceive antenatal clinics (ANCs) as women's spaces and 'reproductive health' as women's health (Muwanguzi et al. 2019; Ramirez-Ferrero \& Lusti-Narasimhan 2012; Walston 2005). The institutionalisation of reproductive health discourages men from utilising healthcare services where men are not the 'target' of the interventions, and this approach has also led to the use of women's bodies as the focus of medical interventions and ignored men's experiences of reproductive health (Culley, Hudson \& Lohan 2013; Throsby \& Gill 2004). Also, programmatic factors have been identified by various researchers as preventing men from being fully involved in reproductive health at healthcare centres. These include, for example, a lack of access into ANCs, inconvenient consultation times at ANCs, poor staff attitudes towards men and a lack of privacy (Bolu et al. 2007; Larsson et al. 2010; Morfaw et al. 2013; Nkuoh et al. 2010; Theuring et al. 2009; Tshibumbu 2006).

According to Garvin (1956), meanings are culturally defined. A study by Marashe (2014) suggests that, 'culture is the bedrock on which people build their views of health matters, including HIV, and through which people elucidate and comprehend health issues that affect them' (Marashe 2014:8). Accordingly, the definition of MPI is also shaped by the way people view health matters and how male partners should respond to these. Since time immemorial, most of the African traditional families in Zimbabwe have been governed by patriarchal systems. For example, in the Shona culture, from childhood, a boy child is trained to be a head, breadwinner and provider for the family, whilst, on the other hand, the girl child is trained to be subordinate and submissive. Similar patriarchal traits also infiltrate into education and employment, as well as religion (Kambarami 2006). In the Christian religion, St Paul's epistle to the Colossians states that 'Wives, submit yourselves unto your own husbands, as is fitting in the Lord. Husbands, love your wives and be not bitter against them' (Col 3:18-19). Both the Shona traditional culture and the Christian religion believe that men are superior and make decisions. It is from such beliefs, world views and practices that definitions of MPI are constructed. However, because of existing cultural diversities, coming to a universal definition of MPI is complicated. Hence, previous studies present an array of definitions that apply to their contexts (Montgomery et al. 2011).

Some studies describe MPI in the PMTCT of HIV as male partners' attendance at ANCs (Byamugisha et al. 2010; Ditekemana et al. 2012; Mullany, Becker \& Hindin 2007), as male partners testing for HIV (Maman, Moodley \& Groves 2011; Msuya et al. 2008) and as male partners paying for costs related to ANCs without necessarily taking any part in the ANC activities (Montgomery et al. 2011). In addition to these forms of MPI, Byamugisha et al. (2010) describe MPI in the following ways: that the male partner knows their partner's antenatal appointment dates, discusses antenatal interventions with their partner, takes the time to discover what happens at an ANC and has sought permission to use condoms during the current pregnancy.
Despite the different meanings attached to MPI in the PMTCT of HIV, the concept of MPI is summarised by Ditekemana et al. (2012) as either a positive or a negative manner in which male partners participate in the PMTCT of HIV. Some of the positive aspects of MPI include male partner testing in an antenatal care setting (Byamugisha et al. 2011; Msuya et al. 2008) and couple counselling (Byamugisha et al. 2010; Nkuoh et al. 2010). In contrast, negative meanings of MPI include gender-based violence, not discussing HIV testing with their partner as well as preventing their partner from testing for HIV (Farquhar, Kiarie \& Richardson 2001) and utilising other HIV prevention services.

The study is informed by the gender and development (GAD) theory where the primary focus is on gender division of labour. Parpart, Connell and Barriteau (2000) explain that:

GAD also recognizes that women are deeply affected by the nature of patriarchal power in their societies at the national, community, and household levels. Moreover, women's material conditions and patriarchal authority are both defined and maintained by the accepted norms and values that define women's and men's roles and duties in a particular society ... (p. 63)

In addition, the GAD theory addresses the root cause of inequalities in gender and other challenges faced by women in their daily lives (Parpart et al. 2000). It does not only focus on women but also focuses on the relationship between men and women. The GAD theory helps to unpack the understanding that individuals and communities have of male partners' roles in the PMTCT of HIV. The meanings and understanding of what individuals or communities have of the concept of MPI are also influenced by their social constructions of gender roles in their specific cultural context.

A study conducted in Uganda sought to define the concept of MPI in PMTCT, as well as to design a theoretical model to explain the concept (Muwanguzi et al. 2019). Although our objective is similar, the context within which meanings are constructed could vary because of varying social norms, value systems and lifestyles between two settings. In this study, I explored the community's understanding of what MPI in PMTCT entails in the rural Zimbabwean cultural setup. The response of male partners to PMTCT programmes is largely influenced by the community's definition of MPI, which in other words is their role in the PMTCT of HIV. Because of the diverse cultural settings within which MPI is defined, an understanding of what this concept means is important as it will impact on the interventions that are designed for HIV preventions. The aim of this study was to explore the meanings associated with MPI in PMTCT.

\section{Methods}

The study employed a qualitative research method and a phenomenological design. A phenomenological approach attempts to understand empirical phenomena from the perspectives of those being studied (Creswell \& Poth 2016; Groenewald 2004). The use of a phenomenological 
approach facilitated participants to describe their views and meanings of MPI, as lived by them. To gather the perspectives of what MPI entailed, the study utilised used focus group discussions (FGDs), key informant interviews (KII) and in-depth interviews (IDIs) with pregnant women as sources of data collection. The FGDs were useful in generating common ideas and views regarding the meaning associated with MPI in PMTCT programmes. The IDI facilitated the drawing of knowledge and views from pregnant mothers who were already part of the PMTCT programmes. The KIIs were conducted with significant individuals who were experts in PMTCT, and who had first-hand knowledge about the community and the activities surrounding the PMTCT programmes.

The study was conducted in Gokwe North, one of the rural districts in the Midlands Province of Zimbabwe. Its population is approximately 245000 people (ZIMSTAT 2012). It is one of the less-developed districts and relies on subsistence farming. The local administration is under traditional chiefs and village headmen.

All the participants had to have resided in the district for at least 1 year. The KIIs were individuals occupying leadership positions in both private and public organisations that were providing PMTCT services, as well as community leaders. The participants of the FGDs were homogenous groups of men and women from churches, healthcare centres, humanitarian organisations, village meetings and projects. Lastly, the interviewees for the IDIs were pregnant mothers admitted in maternity wards.

Participants were selected using the purposive sampling technique, aided by chain referral techniques. For the FGDs, responsible authorities and leaders of various groups were entry points that assisted in identifying and inviting potential participants from their organisations. In order to get participants for the KIIs, management personnel from certain organisations that implemented PMTCT programmes were approached and asked for their participation in the study. At the end of the interview, the researcher would ask for referrals to potential participants who were subsequently requested to take part in the study. Participants for the IDIs were obtained with the guidance of the healthcare personnel management at the hospitals. These organised a meeting with the pregnant mothers and informed them of the study. Individuals who were willing to be interviewed presented themselves to the researcher.

Three different sets of interview guides were used for data collection from the three groups of participants. Participants were interviewed at places that were private and convenient for them. On average, each interview lasted for approximately one and a half hours and each was audiorecorded. In addition, participant observation aided to gather information expressed through non-verbal cues. Notes were written to capture these.
Thematic analysis was used for analysis of the data. The analysis process involved becoming familiar with the data, which was performed by conducting a thorough reading of the notes and the verbatim interview transcripts. The main themes emerging for the data were identified and coded in NVIVO software. This enabled organising the data into relevant subthemes by grouping statements with similar meanings or ideas. Direct short and extensive quotes were extracted from the interviews, so as to ensure that the contextual meanings of vital issues were retained.

This study was part of a doctoral research project that was conducted at the University of KwaZulu-Natal. All the research procedures were executed according to the ethical guidelines. Information regarding informed consent was shared with participants. Confidentiality in the collection of data and reporting of findings was observed.

\section{Results Participants}

A total of 80 participants were studied, of which the majority ( $41 \%)$ were female participants. The IDIs were conducted with female participants only as these were women admitted in the maternity ward. Women constituted the highest number (55\%) of all the FGD participants. There was no difference in the gender ratio for the KIIs. The average mean age for all the groups was 35 years and the KIs had the highest mean age of $43 \%$. The ages of the participants ranged from 18 years and above. A relatively high number of participants were between 26 and 35 years of age (30\%) and 36 and 45 years of age $(32 \%)$, respectively. Very few $(7 \%)$ of the participants were above 56 years of age.

The study participants described MPI in various ways. Health service providers, the men and women in the FGDs and the pregnant women in the IDIs all agreed that male partner participation in PMTCT programmes could be understood in terms of participation in couple HIV counselling and testing, agreeing to use condoms during pregnancy, breastfeeding amongst HIV-positive or seropositive

TABLE 1: Characteristics of participants.

\begin{tabular}{|c|c|c|c|c|c|c|c|c|}
\hline \multirow[t]{2}{*}{ Characteristic } & \multicolumn{2}{|c|}{ FGDs } & \multicolumn{2}{|c|}{ KIIs } & \multicolumn{2}{|c|}{ IDIs } & \multicolumn{2}{|c|}{ Total } \\
\hline & $N$ & $\%$ & $N$ & $\%$ & $N$ & $\%$ & $N$ & $\%$ \\
\hline \multicolumn{9}{|l|}{ Gender } \\
\hline Male & 30 & 45 & 3 & 50 & 0 & - & 33 & 41 \\
\hline Female & 36 & 55 & 3 & 50 & 8 & 100 & 47 & 59 \\
\hline \multicolumn{9}{|l|}{ Age range (years) } \\
\hline $18-25$ & 11 & 17 & 0 & - & 3 & 38 & 14 & 18 \\
\hline $26-35$ & 21 & 32 & 0 & - & 3 & 38 & 24 & 30 \\
\hline $36-45$ & 20 & 30 & 4 & 66 & 2 & 24 & 26 & 32 \\
\hline $46-55$ & 9 & 14 & 1 & 22 & 0 & - & 10 & 13 \\
\hline $56+$ & 5 & 7 & 1 & 22 & 0 & - & 6 & 7 \\
\hline Mean age (years) & 33 & - & 43 & - & 30 & - & 35 & - \\
\hline
\end{tabular}

FGD, focus group discussions; KII, key informant interviews; IDI, in-depth interviews. 
couples, having knowledge of how to provide medicine to the child, financial support, fidelity in marriage as well as accessing education on PMTCT of HIV.

\section{Male partner tests for human immunodeficiency virus during female partner's pregnancy}

Most of the respondents associated MPI with HIV testing during their female partner's pregnancy. Human immunodeficiency virus counselling and testing for couples during pregnancy was considered as one of the most profound ways in which couples were informed of their HIV status and received counselling on how to prevent infecting their unborn child with HIV. The following quote illustrated this view:

'The man receives the services offered during pregnancy, especially HIV testing, but they also get at the same time education on HIV prevention and the next steps that are required. If they are HIV positive they may also start on the treatment. For those that are HIV negative, they can learn how to prevent HIV infection ... However, male involvement goes beyond just being tested. It also means being able to prevent HIV as well.' (Female, 41 years, KII \#1)

Other than knowing their status, HIV testing also provided an opportunity for men to get educated on prevention and get the necessary treatment if they tested positive. Counselling on prevention of disease transmission was also shown as one of the services that came with HIV testing. Although HIV testing was generally the common way in which male partners were strongly encouraged to participate in the programme, lack of disclosure of an HIV-positive status was found to defeat the purpose of HIV testing and prevention amongst couples. The quote below demonstrated this view:

'[W]e get tested together, he will know his status and the same applies to me, I will also know my status. However, if he has been unfaithful, he may be afraid of testing. Otherwise it is important to get tested so that we get early prevention. If he tests alone it is wise to disclose his status so as to prevent conflict in marriage.' (Female, 28 years, IDI \#4)

The quotes above showed that MPI was directly linked to HIV testing. Most of the initiatives towards male partner participation were performed with a view of getting male partners to get tested with their wives.

The results also meant that male partner testing during pregnancy formed the basis of MPI, especially within healthcare institutions. Human immunodeficiency virus prevention was also emphasised after the couple had learnt of their HIV status, and it was only after learning of their HIV-positive status that couples got counselling on prevention methods they could use, depending on their serostatus. It was, however, also found that men were not always keen to get tested:

'[T]his participation means getting consent from males in being tested the same way women are being tested when the female partner is pregnant ... Although men do not generally want to get tested, involving them is critical where the partner is HIV positive.' (Male, 52 years, KII \#2)
'When the woman gets pregnant, the man should encourage her to go and test on time. So men should play that role to their wives. In addition, they should test as a couple and this is what is being advised these days. Some men even deny to get tested. Hence, men should be supportive when it comes to such issues.' (Male, 54 years, FGD \#3)

The quotes above showed that HIV voluntary counselling and testing was an important component of MPI in PMTCT. An important observation drawn in these findings was that HIV testing was highly encouraged during pregnancy, but little attention was given to the need to test continuously during the postpartum period for those who tested negative. As much as testing for HIV enabled the people to know their status and take the necessary measures to prevent infection, some men may not have been inclined to test for fear of conflict in their marriage if they received positive results after testing. Regardless of refusal to test or fear of testing that could be experienced from men, the respondents' views demonstrated that HIV testing was a key responsibility that men were expected to fulfil to prevent infection amongst children.

\section{Male partner agreeing to use condoms}

Most of the respondents in the FGDs as well as in the IDIs highlighted that condom use was an aspect of HIV prevention that men needed to be educated about. They noted that it was not because men had no idea about condoms but rather that they were not keen to use them with a married partner.

Several of the respondents thus stated in their discussions that there was a specific need to educate male partners on condom use amongst couples, and the following quotes illustrated this view:

' $[W]$ e believe that the man has more power than the woman. In this regard, it is important that when the couple is HIV positive or if one of them is positive, the man be the first to be taught about safe sex. Once they get that knowledge, they use it in their capacity as men to negotiate for safer sex than for the woman to start negotiating for safe sex. Some of the men are difficult to convince and so if the idea of using condoms is coming from the men it becomes easy.' (Female, 35 years, FGD \#7)

' $[A]$ s for me, a man can get involved in many ways ... For example, a man should use condoms when they go and have extra-marital sexual unions. If some men are told about this issue of protection, they get furious and swear not to be part of the male involvement programme. This is actually killing many women in the homes.' (Female, 29 years, IDI \#5)

The quotes demonstrated the challenges associated with condom use between couples for the prevention of HIV, as well as the importance of using them. They also pointed out that the use of condoms was sometimes associated with extra-marital unions, with mostly women revealing that it was men who were involved in extra-marital relations rather than the women, and that men should use condoms when they had sexual intercourse with another woman and not with the partner to whom they were married. This was quite an interesting finding as it showed the society's expectations 
of men and women in marital unions where traditional, cultural beliefs denoted that a man with many wives or female partners was seen as a symbol of virility and manliness. These results could, however, also have meant that women were also involved in such affairs but most likely had under-reported them.

\section{Knowledge of administering infant antiretroviral medicine}

Male partner's knowledge of how to administer the medicine prescribed to the child was described by female respondents as an important form of MPI. Most female respondents in the FGDs and IDIs explained that an HIV-infected mother could become ill to the point that she failed to give medicine to her child, besides being unable to take care of the child. This study's results showed that respondents were concerned that most men were not taught how to give nevirapine (NVP) to the children, yet it was an important component of HIV prevention amongst children. The following quotes illustrated this view:

'The man must have knowledge on how to provide medicine to the baby and can also help with collection of the medicine if the mother is not yet strong after delivery.' (Female, 40 years, FGD \#2)

'[T] he man must also have knowledge on how to prevent HIV from the child because for instance, I can know what is supposed to be done but the man has no idea of how to provide medication to the child. If I die, it will be a problem because he does not know how to ensure that the child is protected.' (Female, 37 years, IDI \#1)

The quotes showed that male partners were not being educated or counselled on how to administer HIV treatment to their children in the same way that women were. The results also suggested that allowing men to learn how to manage the children's treatment was not about sharing responsibility, but rather for the purpose of helping when the women were not capable of doing so in the event of their sickness or absence.

\section{The male partner gives financial support}

The findings of this study revealed that male and female respondents associated MPI with the financial support that the husband gave to his female partner from the time of pregnancy to breastfeeding. The main duties of the male partner within a household pertained to providing for the needs of the family, and as such, the same understanding was applied in the context of PMTCT programmes. It was important to note that some of the respondents (both male and female) were convinced that there was nothing wrong if the man did not attend the hospital or clinic, as long as he paid the necessary hospital bills. This entailed the male partner paying for the costs associated with antenatal or postnatal services, as shown in the following quotes:

'The man can help to provide healthy food to the mother and child so that their immune system remains strong.' (Female, 24 years, IDI \#6)
'The man has a role to play in buying the milk for the baby instead of relaxing and saying that there is nothing he can do and let the woman breastfeed, which puts the child at risk of getting infected.' (Male, 45 years, FGD \#2)

'If the man does not want to go to the clinic with the female partner, he can just give her money for transport. Also, he needs to ensure that his female partner is well-dressed when she goes to the clinic because sometimes women do not want to register the pregnancy because they do not have maternity wear.' (Female, 44 years, FGD \#1)

These quotes showed that respondents believed that it was the duty of the male partners to provide financial support for their partners so that they could pay for the necessary costs. Apart from money to buy food, as mentioned above, the male partners were not required to go with their wives for antenatal care as long as they provided money to pay for the necessary care and items. Hence, the provision of money was considered sufficient support, meaning that the male partners were not expected to attend antenatal care sessions.

\section{Faithfulness in marriage}

Faithfulness in marriage was described as central to preventing mother-to-child transmission of HIV. Evidence from the study suggested that unfaithful partners contributed to the spread of HIV because they had more than one sexual partner, which put them at risk of HIV infection. It was interesting to note that both male and female respondents in the FGDs pointed out that it was men who were usually associated with extramarital affairs. In this regard, they considered faithfulness to one partner as one of the ways in which a male partner could contribute to preventing HIV:

'It was mentioned that the two need to be faithful to each other
so as to maximise prevention. If the two are not faithful to each
other, then it compromises the goal of prevention. Some of our
brothers are not content with having one partner, who in this
case is the female partner ... Now in the era of HIV; the best way
a man can save his family from HIV is by sticking to one partner
that is, his female partner. It is said that a man cannot stick to one
partner but some of us are trying and we are managing. It is just
a matter of disciplining yourself and be[ing] with friends that do
not lead you into dating other women.' (Male, 43 years, FGD \#5)
'Most of our men are not committed to one female partner. This
puts women and children at risk of getting HIV because at some
point I do not know whether we are safe from HIV or not. It is
not easy to make him change his behaviour but now that there is
HIV, the only thing I expect of him is to be faithful to me only ...'
(Female, 39 years, IDI \#2)

Infidelity in marriage was considered as a practice that put couples at risk of HIV infection, which then led to mother-to-child transmission of HIV. Infidelity or unfaithfulness in marriage in this context referred to a partner who was involved in multiple sexual partnerships whilst they were married. A positive way in which male partners were expected to participate in the PMTCT of HIV was to reduce sexual partners, as the results suggested that it was the male partners who seemed to be involved in extramarital sexual unions. 


\section{Advancement of male partners' knowledge of prevention of mother-to-child transmission}

Respondents from this study elaborated that there had been various invitations sent out in the communities, encouraging male partners to take part in PMTCT services. These included accompanying their spouses to ANCs during pregnancy and taking part in HIV couple counselling and testing. The respondents, however, also highlighted that there had been little focus on educating men. They felt that MPI should not only be understood in terms of providing emotional or material support; they should be given education on PMTCT as well. Women thus received more education on PMTCT than men, and concerns regarding the lack of education amongst the male partners on PMTCT were illustrated in the following quotes:

'Those who provide education on health and conduct awareness campaigns do not call meetings specifically for men. It is usually women they invite. We only learn from the radio. They should just organise a day when they teach men alone. Like some of the issues we are discussing here now, we are not sure whether it is true or not because there is none of us who has sufficient education on the subject. This is what we hear from other people and not what we have learnt directly. There was never a day where men only were called to discuss about health issues.' (Male, 37 years, FGD \#3)

'There are so many meetings where women are invited to attend. For example, they will call them to get family planning tablets and teach them about PMTCT during those encounters. Women are also asked to bring children for immunisation and during that time they teach them. If men are present during those sessions, they will be excused from those meetings because they say they want few minutes with women. Even though they may not excuse men, it feels so weird [for a man] to be among women.' (Male, 45 years, FGD \#5)

These findings revealed the importance that was placed on providing information to male partners and engaging them in the health-related activities that were conducted in the communities. It also appeared that providing education to men by means of creating opportunities where men shared and learned was seen as an important part of MPI in the programmes aimed at HIV prevention. Another interesting point to note was that health practitioners made use of the women's appearances at clinics or villages for family planning programmes and children's immunisations as opportunities to provide information and educate them on health matters.

\section{Discussion}

The aim of this study was to gain insights into the concept of MPI in PMTCT in the Gokwe North District. The findings presented major descriptions of what the respondents considered as MPI in the PMTCT of HIV. Male partner testing for HIV with their partners during pregnancy was highly considered as a form of MPI. Male partner involvement was also associated with condom use during pregnancy and after birth for breastfeeding couples, as this would help to reduce the chances of mother-to-child infection during those periods.
The provision of financial support for PMTCT costs and being faithful to one partner were also considered as MPI.

There is a strong agreement amongst various researchers and policy-makers that MPI in PMTCT is a fluid concept and the definition varies across different contexts (Byamugisha et al. 2011; Farquhar, Kiarie \& Richardson 2004; Maman et al. 2011; Msuya et al. 2008; Nkuoh et al. 2010). The findings of this study showed male partners' attendance at HIV counselling and testing with their wives and their agreement to being tested for HIV as common definitions of MPI. The implications of these findings were that single definitions of MPI could not be used in isolation but that MPI could rather be considered as certain activities or acts that male partners carried out as their contribution to the PMTCT of HIV.

Furthermore, male partner participation in HIV couple counselling and testing was echoed as a cross-cutting meaning of MPI in PMTCT. This was because of the fact that HIV couple counselling and testing is considered as an entry point to many other activities within PMTCT initiatives. These findings were not striking at all as a number of previous studies (Aluisio et al. 2011; Byamugisha et al. 2011; Ditekemana et al. 2012; Farquhar et al. 2004; Maman et al. 2011; Msuya et al. 2008; Nkuoh et al. 2010) also considered male partner counselling and testing for HIV with their wives during pregnancy as one of the forms of MPI in the PMTCT of HIV. The main reason why this study and previous studies considered male partner counselling and testing at ANCs as an important aspect of MPI was based on the positive outcomes associated with this practice. For example, in a study in Moshi, urban Tanzania, Msuya et al. (2008) demonstrated that HIV-seropositive women whose partners attended voluntary counselling sessions and tested for HIV were three times more likely to use NVP prophylaxis, and six times more likely to adhere to the infant feeding method selected than those whose partners did not attend.

Educating male partners on PMTCT and other services linked to HIV prevention was considered as one of the fundamentals of MPI in the PMTCT of HIV. This included knowledge of how to administer antiretroviral drugs to their children when necessary. The findings of this study revealed that the men in the district had not received adequate education on PMTCT when compared with their female counterparts. In a policy proposal for increasing MPI in PMTCT, Van den Berg et al. (2015) suggested that the health departments and civil society organisations make concerted efforts to educate men and raise awareness of maternal and child health. Educating men was also expected to facilitate the reversing of gender norms that discouraged men from accessing health services (Van den Berg et al. 2015; Nyondo, Chimwaza \& Muula, 2014). The findings thus underscored the importance of ensuring that men were equipped with the necessary information on PMTCT, as well as how their role as partners and fathers was crucial in curbing HIV infections. 
The findings also highlighted that MPI was associated with the male partner agreeing to use condoms during pregnancy to reduce the chances of HIV infection. Nonetheless, the respondents stated that there were challenges associated with condom use, as men were not keen to use them. At the same time, it was revealed that extramarital sexual unions were common and that this was a practice that exposed women and children to HIV infection. This study showed that condom use amongst married couples was not always acceptable, compared with when they were used in an extramarital affair or with casual sexual partners. These results were consistent with the previous studies that highlighted low condom use and its low acceptability in marriage (Chimbiri 2007; Maharaj \& Cleland 2005; Muhwava 2004; Mugweni, Omar \& Pearson 2015; Williamson et al. 2006). Some of these studies also suggested that women were more likely to have a positive attitude towards condom use than their male counterparts (Maharaj \& Cleland 2005), but at the same time, discussion of condom use in marriage and stable partnerships was relatively non-existent (Muhwava 2004). Given that marriage in Zimbabwe was common, these results underscored the need to broaden HIV prevention interventions to include married men and women.

The second aspect of gender roles related to the male partner's involvement in the PMTCT of HIV was linked to providing financial support to the mother and child. This included buying replacement feeding, transport costs, clothing, and treatment and other costs linked to PMTCT. Various studies in the past showed that one major positive contributor to the male partners' involvement in PMTCT was providing transport to the health facility, as well as paying for antenatal costs (Maman et al. 2011; Montgomery et al. 2011). This form of MPI was not unusual and it was also one of the duties that defined men's roles as providers for their families in many African settings.

Faithfulness to a partner was considered as a primary means of HIV prevention. In this regard, it was highlighted that the greater the fidelity in marriage, the lower the risk of infection for women and children. This idea came from the understanding that males were more likely than females to have extramarital sexual contacts, and these findings were consistent with the previous studies that promoted faithfulness in marriage and partner reduction as a primary method of prevention of HIV infection (Cohen 2004; De Zoysa, Sweat \& Denison 1996; Genuis \& Genuis 2005; Gregson et al. 2006; Painter et al. 2007). In addition, this study demonstrates the influence of religion in making meanings of MPI. The Book of Proverbs (5:15) states that, 'Be faithful to your own wife and give your love to her alone'. In his epistle to the Hebrews (13:4), Paul writes, 'Give honour to marriage and remain faithful to one another in marriage'. It is important to note that the idea of fidelity in marriage may not primarily constitute MPI in other settings because of diverse HIV-related challenges that communities encounter. For instance, studies in Uganda by Green et al. (2013) noted a shift in the country's
AIDS strategy, showing a rise in the promotion of condom use and HIV testing and less emphasis on behaviour change, especially regarding fidelity. Whilst consistent condom use is an effective means of reducing the risk of HIV infection in generalised epidemics, Kajubi et al. (2005) argued that the gains of condom use could be offset by an increase in the number of sexual partners. These results indicate the significance of understanding meanings of MPI within specific context as this can facilitate in designing intervention initiatives that are culturally acceptable.

\section{Conclusion}

The aim of this study was to explore the meanings associated with MPI in PMTCT. Results from the study provided a holistic approach to the understanding of MPI in PMTCT. The study portrayed that MPI was not only confined during the antenatal period but also during the postnatal period. In addition, male partners were also expected to benefit from the programmes by being equipped with knowledge and having their health needs met within these interventions.

It emerged from the study that MPI could be understood as an act of the male partner receiving HIV couple counselling and testing with his partner. Their participation in couple counselling and testing was considered as an entry point through which they could be part of other interventions that extended from HIV testing. These included taking responsibility by using condoms during pregnancy, gaining knowledge on how to administer infant NVP as well as gaining basic knowledge of HIV. The study also showed providing financial resources as one of the markers of male partner support in PMTCT-related costs. Also, it was striking to learn about the lack of initiatives undertaken to provide men with health education. The study showed that understanding the world views and meanings surrounding MPI was important in designing interventions aimed at improving participation by men in HIV interventions. Future research could explore male health service provision within HIV intervention programmes as a means of increasing their engagement.

\section{Acknowledgements Competing interests}

The author declares that she has no financial or personal relationships that may have inappropriately influenced her in writing this research article.

\section{Author's contribution}

V.C. is the sole author of this research article.

\section{Ethical considerations}

This article followed all ethical standards for research without direct contact with human or animal subjects. 


\section{Funding information}

This research received no specific grant from any funding agency in the public, commercial or not-for-profit sectors.

\section{Data availability}

Data is available upon reasonable request.

\section{Disclaimer}

The views and opinions expressed in this article are those of the author and do not necessarily reflect the official policy or position of any affiliated agency of the author.

\section{References}

Aluisio, A., Richardson, B.A., Bosire, R., John-Stewart, G., Mbori-Ngacha, D. \& Farquhar, C., 2011, 'Male antenatal attendance and HIV testing are associated with decreased infant HIV infection and increased HIV free survival', Journal of Acquired Immune Deficiency Syndromes (1999) 56(1), 76. https://doi.org/10.1097/ Acquired Immune Deficie
QAl.0b013e3181fdb4c4

Bolu, O.O. Allread, V., Creek, T, Stringer, E, Forna, F, Bulterys, M. \& Shaffer, N., 2007, 'Approaches for scaling up human immunodeficiency virus testing and counseling in prevention of mother-to-child human immunodeficiency virus transmission settings in resource-limited countries', American Journal of virus transmission settings in resource-limited countries', American Journal of
Obstetrics and Gynecology 197(3), S83-S89. https://doi.org/10.1016/j.ajog. Obstetrics and
2007.03.006

Bwambale, F.M., Ssali, S.N., Byaruhanga, S., Kalyango, J.N. \& Karamagi, C.A., 2008 'Voluntary HIV counselling and testing among men in rural western Uganda: Implications for HIV prevention', BMC Public Health 8(1), 1. https://doi. org/10.1186/1471-2458-8-263

Byamugisha, R., Åstrøm, A.N., Ndeezi, G., Karamagi, C.a.S., Tylleskär, T. \& Tumwine, J.K., 2011, 'Male partner antenatal attendance and HIV testing in eastern Uganda: A randomized facility-based intervention trial', Journal of the International AIDS Society 14(1), 43. https://doi.org/10.1186/1758-2652-14-43

Byamugisha, R., Tumwine, J.K., Semiyaga, N. \& Tylleskar, T., 2010, 'Determinants of male involvement in the prevention of mother-to-child transmission of HIV programme in Eastern Uganda: A cross-sectional survey', Reproductive Health 7(1), 12. https://doi.org/10.1186/1742-4755-7-12

Chimbiri, A.M., 2007, 'The condom is an "intruder" in marriage: Evidence from rural Malawi', Social Science \& Medicine 64(5), 1102-1115. https://doi.org/10.1016/j. socscimed.2006.10.012

Cohen, S., 2004, 'Beyond slogans: Lessons from Uganda's experience with $A B C$ and HIV/AIDS', Reproductive Health Matters 12(23), 132-135. https://doi.org/ 10.1016/S0968-8080(04)23126-3

Creswell, J.W. \& Poth, C.N., 2016, Qualitative inquiry and research design: Choosing among five approaches, Sage Publications, Lincoln.

Culley, L., Hudson, N. \& Lohan, M., 2013, 'Where are all the men? The marginalization of men in social scientific research on infertility', Reproductive BioMedicine Online 27(3), 225-235. https://doi.org/10.1016/j.rbmo.2013.06.009

De Zoysa, I., Sweat, M.D. \& Denison, J.A., 1996, 'Faithful but fearful: Reducing HIV transmission in stable relationships', AIDS 10(Suppl. A), S197-S204. https://doi. org/10.1097/00002030-199601001-00028

Ditekemana, J., Koole, O., Engmann, C., Matendo, R., Tshefu, A., Ryder, R. et al., 2012 'Determinants of male involvement in maternal and child health services in subSaharan Africa: A review', Reproductive Health 9(1), 1-8. https://doi.org/10.1186/ 1742-4755-9-32

Farquhar, C., Kiarie, J.M., Richardson, B.A., Mbori-Ngacha, D.A. \& John-Stewart, G.C., 2001, 'Antenatal couple counseling increases uptake of interventions to prevent HIV-1 transmission', AIDS Care 15(6), 815-817. https://doi.org/10.1097/00002030200104130-00027

Farquhar, C., Kiarie, J.N. \& Richardson, B.A., 2004, 'Antenatal couple counseling increases uptake of interventions to prevent HIV-1 transmission', Journal of Acquired Immune Deficiency Syndrome 37(5), 1620-1626. https://doi org/10.1097/00126334-200412150-00016

Garvin, P.L., 1956, Report of the seventh annual round table meeting on linguistics and language teaching, Georgetown University Press, Washington, DC.

Genuis, S.J. \& Genuis, S.K., 2005, 'HIV/AIDS prevention in Uganda: Why has it worked?', Postgraduate Medical Journal 81(960), 615-617. https://doi.org/10.1136/ pgmj.2005.034868

Green, E.C., Kajubi, P., Ruark, A., Kamya, S., D'Errico, N. \& Hearst, N., 2013, 'The need to reemphasize behavior change for HIV prevention in Uganda: A qualitative study', Studies in Family Planning 44(1), 25-43. https://doi.org/10.1111/j.17284465.2013.00342.x

Gregson, S., Garnett, G.P., Nyamukapa, C.A., Hallett, T.B., Lewis, J.J., Mason, P.R. et al., 2006 , 'HIV decline associated with behavior change in eastern Zimbabwe', Science 311(5761), 664-666. https://doi.org/10.1126/science.1121054
Groenewald, T., 2004, 'A phenomenological research design illustrated', International Journal of Qualitative Methods 3(1), 42-55. https://doi.org/10.1177/ 160940690400300104

Kajubi, P., Kamya, M.R., Kamya, S., Chen, S., Mcfarland, W. \& Hearst, N., 2005, 'Increasing condom use without reducing HIV Risk: Results of a controlled community trial in Uganda', JAIDS Journal of Acquired Immune Deficiency Syndromes 40(1), 77-82. https://doi.org/10.1097/01.qai.0000157391.63127.b2

Kambarami, M., 2006, Femininity, sexuality and culture: Patriarchy and female subordination in Zimbabwe, Africa Regional Sexuality Resource Centre, Lagos.

Larsson, E.C., Thorson, A., Nsabagasani, X., Namusoko, S., Popenoe, R. \& Ekström, A.M., 2010, 'Mistrust in marriage: Reasons why men do not accept couple HIV testing during antenatal care: A qualitative study in eastern Uganda', BMC Public Health 10(1), 1. https://doi.org/10.1186/1471-2458-10-769

Maharaj, P. \& Cleland, J., 2005, 'Risk perception and condom use among married or cohabiting couples in KwaZulu-Natal, South Africa', International Family Planning Perspectives 31(1), 24-29. https://doi.org/10.1363/3102405

Maman, S., Moodley, D. \& Groves, A.K., 2011, 'Defining male support during and after pregnancy from the perspective of HIV-positive and HIV-negative women in Durban, South Africa', Journal of Midwifery and Women's Health 56(4), 325-331. https://doi.org/10.1111/j.1542-2011.2011.00029.x

Marashe, J., 2014, 'The African traditional religious landscape: An examination of the role of traditional leaders in the fight against HIV and AIDS in Chipinge, Zimbabwe', Verbum et Ecclesia 35(1), 1-8. https://doi.org/10.4102/ve.v35i1.871

Montgomery, E., Van der Straten, A. \& Torjesen, K., 2011, 'Male involvement in women and children's HIV prevention: Challenges in definition and interpretation', JAIDS Journal of Acquired Immune Deficiency Syndromes 57(5), e114-e116. https://doi.org/10.1097/QAl.0b013e31821d33d6

Morfaw, F., Mbuagbaw, L., Thabane, L., Rodrigues, C., Wunderlich, A.-P., Nana, P. et al., 2013 , 'Male involvement in prevention programs of mother-to-child transmission of HIV: A systematic review to identify barriers and facilitators', Systematic of HIV: A systematic review to identify barriers and
Reviews 2(1), 1. https://doi.org/10.1186/2046-4053-2-5

Msuya, S.E., Mbizvo, E.M., Hussain, A., Uriyo, J., Sam, N.E. \& Stray-Pedersen, B., 2008 'Low male partner participation in antenatal HIV counselling and testing in northern Tanzania: Implications for preventive programs', AIDS Care 20(6), northern Tanzania: Implications for preventive progr
700-709. https://doi.org/10.1080/09540120701687059

Mugweni, E., Omar, M. \& Pearson, S., 2015, 'Understanding barriers to safer sex practice in Zimbabwean marriages: Implications for future HIV prevention interventions', Health Education Research 30(3), 388-399. https://doi.org/ interventions', Health
$10.1093 /$ her/cyu073

Muhwava, W., 2004, 'Condom use within marriage and consensual unions in the era of HIV/AIDS in Zimbabwe', African Population Studies 19(1), 119-141.

Mullany, B.C., Becker, S. \& Hindin, M., 2007, 'The impact of including husbands in antenatal health education services on maternal health practices in urban Nepal: Results from a randomized controlled trial', Health Education Research 22(2), 166-176. https://doi.org/10.1093/her/cyl060

Muwanguzi, P.A., Nassuna, L.K., Voss, J.G., Kigozi, J., Muganzi, A., Ngabirano, T.D. et al., 2019, 'Towards a definition of male partner involvement in the prevention of mother-to-child transmission of HIV in Uganda: A pragmatic grounded theory approach', BMC Health Services Research 19(1), 557. https://doi.org/10.1186/ s12913-019-4401-x

Nkuoh, G.N., Meyer, D.J., Tih, P.M. \& Nkfusai, J., 2010, 'Barriers to men's participation in antenatal and prevention of mother-to-child HIV transmission care in Cameroon, Africa', Journal of Midwifery \& Women's Health 55(4), 363-369. https://doi.org/10.1016/j.jmwh.2010.02.009

Nyondo, A.L., Chimwaza, A.F. \& Muula, A.S., 2014, 'Stakeholders' perceptions on factors influencing male involvement in prevention of mother-to-child transmission of HIV services in Blantyre, Malawi', BMC Public Health 14(1), 691 https://doi.org/10.1186/1471-2458-14-691

OPHID, 2015, Male participation in PMTCT: Survey on the experiences, attitudes and perspectives of male partners in antenatal and PMTCT services Mashonaland East Province, Zimbabwe, Organisation for Public Health Interventions and Development, Harare.

Orne-Gliemann, J., Tchendjou, P.T., Miric, M., Gadgil, M., Butsashvili, M., Eboko, F. et al., 2010, 'Couple-oriented prenatal HIV counseling for HIV primary prevention: An acceptability study', BMC Public Health 10(1), 197. https://doi. org/10.1186/1471-2458-10-197

Påfs, J., Musafili, A., Binder-Finnema, P., Klingberg-Allvin, M., Rulisa, S. \& Essén, B., 2015, "They would never receive you without a husband": Paradoxical barriers to antenatal care scale-up in Rwanda', Midwifery 31(12), 1149-1156. https://doi.org/10.1016/j.midw.2015.09.010

Painter, T.M., Diaby, K.L., Matia, D.M., Lin, L.S., Sibailly, T.S., Kouassi, M.K. et al., 2007, 'Faithfulness to partners: A means to prevent HIV infection, a source of HIV infection risks, or both? A qualitative study of women's experiences in Abidjan, Côte d'Ivoire', African Journal of AIDS Research 6(1), 25-31. https:// doi.org/10.2989/16085900709490396

Parpart, J.L., Connell, M.P. \& Barriteau, V.E., 2000, Theoretical perspectives on gender and development, International Development Research Centre,
Ottawa.

Ramirez-Ferrero, E. \& Lusti-Narasimhan, M. 2012, 'The role of men as partners and fathers in the prevention of mother-to-child transmission of HIV and in the promotion of sexual and reproductive health', Reproductive HIV and in the promotion of sexual and reproductive health', Reproductive
Health Matters 20(39), 103-109. https://doi.org/10.1016/S0968-8080(12) Health

Theuring, S., Mbezi, P., Luvanda, H., Jordan-Hader, B., Kunz, A. \& Harms, G., 2009 'Male involvement in PTMCT services in Mbeya Region, Tanzania', AIDS and Behaviour 13(1), 92-102. https://doi.org/10.1007/s10461-009-9543-0 
Throsby, K. \& Gill, R., 2004, “It's different for men" masculinity and IVF', Men and Masculinities 6(4), 330-348. https://doi.org/10.1177/1097184X03260958

Tshibumbu, D.D., 2006, 'Factors influencing men's involvement in prevention of mother-to-child transmission (PMTCT) of HIV programmes in Mambwe district, Zambia', Master's Degree in Public Health, University of South Africa.

Van den Berg, W., Brittain, K., Mercer, G., Peacock, D., Stinson, K., Janson, H. et al., 2015, 'Improving men's participation in preventing mother-to-child transmission of HIV as a maternal, neonatal, and child health priority in South Africa', PLoS Medicine 12(4), e1001811. https://doi.org/10.1371/journal.pmed.1001811
Walston, N., 2005, Challenges and opportunities for male involvement in reproductive health in Cambodia, POLICY Project/Cambodia, Phnom Penh.

Williamson, N.E., Liku, J., Mcloughlin, K., Nyamongo, I.K. \& Nakayima, F., 2006 'A qualitative study of condom use among married couples in Kampala, Uganda', Reproductive Health Matters 14(28), 89-98. https://doi.org/10.1016/S09688080(06)28268-5

ZIMSTAT, 2012, Population census preliminary report, Zimbabwe National Statistics Agency, Harare. 